\title{
Behind the veil of extreme event attribution
}

\author{
Aglaé Jézéquel ${ }^{1}$, Vivian Dépoues ${ }^{2,3,4}$, Hélène Guillemot ${ }^{5}$, Mélodie Trolliet $^{6}$, \\ Jean-Paul Vanderlinden ${ }^{4}$, and Pascal Yiou ${ }^{1}$ \\ ${ }^{1}$ Laboratoire des Sciences du Climat et de lEnvironnement, UMR \\ CEA-CNRS-UVSQ, IPSL \& U Paris-Saclay, CE l'Orme des Merisiers, 91191 \\ Gif-sur-Yvette
}

${ }^{2}$ ADEME 20 Avenue du Grésillé, 49000 Angers

${ }^{3}$ I4CE Institute for Climate Economics, 24 Avenue Marceau, 75008 Paris, France

${ }^{4}$ CEARC, OVSQ University Versailles Saint-Quentin-en-Yvelines, 11 Boulevard d'Alembert, 78280 Guyancourt, France

${ }^{5}$ Centre Alexandre Koyré - CNRS - 27 Rue Damesme, 75013 Paris

${ }^{6}$ MINES ParisTech, PSL Research University, O.I.E. - Center for Observation, Impacts, Energy, Sophia Antipolis, France

\section{April 12, 2018}

\begin{abstract}
Since [Allen, 2003]'s seminal article, the community of extreme event attribution (EEA) has grown. Several approaches have been developed: the main ones being the "risk-based approach" - estimating how the probability of event occurrence correlates with climate change — and the "storyline approach" - evaluating the influence of climate change on thermodynamic processes leading to the event. In this article, we map the different ways to frame attribution used in a collection of 105 case studies from 5 BAMS (Bulletin of American Meteoro-
\end{abstract}


logical Society) special issues on extreme events. In order to do so, we propose to define EEA, based on corpora of interviews conducted with researchers working in the field as follows: EEA is the ensemble of scientific ways to interpret the question "was this event influenced by climate change?" and answer it. In order to break down the subtleties of EEA, we decompose this initial question into three main problems a researcher has to deal with when framing an EEA case study. First, one needs to define the event of interest. Then, one has to propose a way to link the extreme event with climate change, and the subsequent level of conditioning to parameters of interest. Finally, one has to determine how to represent climate change. We provide a complete classification of BAMS case studies regarding those three problems. 


\section{Introduction}

Extreme event attribution (EEA) is a relatively new field of climate science. It started with Allen [2003] after an episode of extreme precipitation that struck southern UK in January 2003. Since then, EEA has grown, and many methodologies have been developed [Stott et al., 2016]. With the growth of the field, different ways to frame EEA have emerged [e.g. Stott et al., 2016, Shepherd, 2016]. The question of framing has been the root of debates among the community [e.g. Trenberth et al., 2015, Otto et al., 2016, Mann et al., 2017, Stott et al., 2017].

The aim of this article is to confront theoretical considerations to actual data, and to discuss the framing of EEA based on case studies to describe and understand what the community is actually doing. In order to do so, we draw on two sets of semi-structured interviews. The first one was conducted among 10 researchers participating to the European project EUCLEIA (called hereafter the EUCLEIA corpus). The second one was done with 9 researchers who did not participate in the first series of interviews (called hereafter the A2C 2 corpus) and are mostly (with one exception) researchers who did not participate to EUCLEIA. The corpora are named after the grants that funded the surveys (see Acknowledgements). Although they share common points, the questions posed to both corpora differ as they were done for different purposes. The EUCLEIA corpus was the first step towards the creation of a European EEA climate service. The A2C2 corpus aimed at investigating what is EEA, and why researchers engage in it. Both grids of questions are provided in the supplementary material; the questions may have varied a little in the flow of the interviews.

We also rely on five issues of the Bulletin of American Meteorological Society (BAMS) annual reports explaining the extremes of the previous year, from 2011 to 2015, which aim at attributing specific events [Peterson et al., 2012, 2013, Herring et al., 2014, 2015, 2016a]. We do not analyse the latest BAMS issue [Herring et al., 2018]. They provide a collection of 105 case studies covering a large spectrum of established methodologies. Those reports give an overview of relatively mature, longstanding methods.

We will first lay out the history and introduce the different framing approaches of EEA. We will 
then explain how we tackled the classification of the case studies and how it led us to propose a working definition, inferred from the ensemble of interviews. We then deduce from this definition an ensemble of questions compulsory to answer in order to frame a case study, and show how the BAMS case studies give a range of answers to those questions.

\section{Framing EEA : an history}

\subsection{The beginning of EEA}

Myles Allen was the first to explicitly frame EEA in a publication in Nature in 2003, titled "Liability of Climate Change". He personally experienced the flooding of the Thames occurring in this period. He asks the question of what caused this event. He subtitled his article: "Will it ever be possible to sue anyone for damaging the climate?" The approach proposed by Allen [2003] takes its roots in a liability perspective. The idea was to compensate the "negative equity" individuals will face when they are confronted to weather-related events linked to anthropogenic emissions. For example, if their house loses value due to being more likely flooded because of climate change, they could sue the biggest greenhouse gas emitters. The main road block identified in this article is the scientific challenge of calculating the change in probabilities. The proposed methodology is to compare the probability of occurrence of an event in both a factual world - i.e. the world as it is with anthropogenic climate change — and a counterfactual world — i.e. the world that would have been without climate change.

A year later, Stott et al. [2004] published the first implementation of this approach. The authors studied the European heatwave of 2003. They proposed an estimation of "how much human activities may have increased the risk of occurrence of such a heatwave". This article uses the concept of fraction of attributable risk (FAR), where risk means probability of occurrence. The FAR is the ratio of the difference between the factual and counterfactual probabilities and the factual probability. A FAR value of 1 means that without anthropogenic climate change the event is impossible. A FAR value of 0 means that anthropogenic climate change had no influence on the event prob- 
ability. A negative FAR means that the event became less likely with anthropogenic climate change.

This first attribution methodology has been refined in more recent articles, facing one of the main problems of attribution, which is the need to have large enough ensembles of simulations to adequately sample all possible weather states for given time period. Pall et al. [2011] rely on very large ensembles of simulations of an atmospheric model for both factual and counterfactual worlds. Those large ensembles have since been used in many studies and there have been developments to use them for operational near real-time attribution systems[e.g. Wolski et al., 2014, Massey et al., 2015, Haustein et al., 2016]. In the rest of the article, this approach will be refered as risk-based approach, following the nomenclature of Shepherd [2016].

\subsection{Later developments of EEA}

A few years later, other ways to put an extreme event in the perspective of anthropogenic climate change have emerged. For example, without explicitly calling it attribution, Perlwitz et al. [2009] showed how the unusual SST pattern of winter 2008 in the Pacific were responsible for the drop in North American temperatures, and that without anthropogenic emissions, the cold would even have been stronger. Similarly, Cattiaux et al. [2010] showed that the cold European winter of 2009/2010 was caused by the atmospheric circulation, and that for the same atmospheric pattern, the temperatures would have been even lower in the past.

In 2015, Trenberth et al. proposed to move the focus of EEA from the risk-based approach i.e. the comparison of probabilities in the factual and counterfactual worlds - to what Shepherd [2016] calls the storyline approach, which seeks to describe how climate change influenced the physical processes leading to the event. Their reasoning is that for some events the signal-to-noise ratio is small due to the internal variability of the atmosphere, so that the risk-based approach usually cannot conclude to any change of probabilities of climate change. It is especially the case for the events mainly driven by dynamics, i.e. that will not happen if not for an extreme atmospheric pattern, like extreme precipitations or storms. Furthermore, the influence of anthropogenic forcing 
on the dynamics is still widely debated in the climate community and the models are not yet up for this task in most cases [e.g. Francis and Vavrus, 2012, Barnes, 2013].

Trenberth et al. [2015] hence propose to evaluate the changes induced by anthropogenic emissions given a circulation pattern. Given the assumption that the influence of climate on dynamics is not detectable, one can then show how climate change influenced the event. The authors put this approach in the perspective of a world that is necessarily different because of climate change: a "new normal". They point out that "all storms, without exception, are different" and argue that the failure to prove that climate change modified the probability of occurrence of an event does not mean that climate change did not play any role.

According to our interviews, one of the factors that led to the storyline approach is the political context in the US, and specifically the policy makers who do not believe in climate change: "the only way to get through to these [deniers] is through the general public. And so it's important to communicate with the general public, and tell them that climate has changed and in fact there are tens of billions of dollars of damages that are caused by climate change every year." In this context Trenberth et al. [2015] find it more important to highlight any way in which climate change had an effect than to calculate a ratio of probabilities. This means that the risk-based approach focuses on quantifying the role of anthropogenic climate change on the probabilities of the event, while the storyline approach aims at unveiling the qualitative ways in which anthropogenic climate change affects the processes leading to the event.

Otto [2017] also introduces a third approach, that she calls the Boulder approach, since it was developed by a group of scientists working at the National Oceanic and Atmosphere Administration (NOAA), in Colorado. She explains that the goal of this approach is to "disentangle different causal factors leading to the event without necessarily quantifying the influence of these causal factors on the likelihood of occurrence". Shepherd [2016] cites papers of this group as examples of storyline approach, so depending on the authors, the storyline approach includes only the circulation conditional framing [Otto, 2017] or is large enough to integrate any study that dissects the physical 
processes leading to an extreme and analyze how anthropogenic climate change influences those processes.

\subsection{Debates regarding the advantages of different framing approaches}

Trenberth et al. [2015]'s paper criticizes heavily the risk-based approach stating that it is "is severely challenged $[\ldots]$ when it comes to climate extremes that are strongly governed by atmospheric circulation, including local aspects of precipitation", that it "is rather ineffectual in cases that are strongly governed by the changed circulation, with generally an inconclusive outcome" and that "even when a detectable anthropogenic influence is found in a model, the reliability of that finding cannot carry much weight". On the other hand, the circulation conditional framing is not without its own critics. Otto et al. [2016] give several examples for which the dynamics are different in the factual and counterfactual worlds, which leads them to state that "limiting attribution studies to the thermodynamic response alone does not allow for an assessment of the actual risk of the event occurring as the large-scale dynamics can counteract or enhance the thermodynamics.”.

Mann et al. [2017] go in the sense of Trenberth et al. [2015] and argue for the use of a Bayesian — rather than frequentist - statistical approach, which would account for information we already have on the physics of both the event and climate change (Risser et al. [2017] also use a Bayesian framework in a risk-based approach article). They mix this argument with ethical considerations regarding the choice of the null hypothesis (prove that climate change had an influence on the event or prove that climate change had no influence on the event). Stott et al. [2017] however point out that the choice of the null hypothesis is independent of the statistical framework and that there are as many biases in Bayesian than in frequentist framings. Curry [2011] also argues that there is no straightforward ethical choice of the null hypothesis in a climate change context (see also the response of Allen [2011] to Curry [2011] on that matter).

This debate is interwoven with a social concern on "which methodological approach would be more useful". Allen [2003] goes as far as arguing that the transposition of EEA to some sort of 
market-based mechanism could be the best solution to cope with the alarmingly slow pace of international climate negotiations. Trenberth et al. [2015] claim that their change of framing would "better serve societal needs" and would "provide a better basis for communication of climate change to the public". Otto et al. [2016] argue that "from the perspective of a stakeholder seeking information to inform disaster risk reduction strategies, it can be unhelpful to ask the question of how the probability has changed given the large-scale circumstances". A few studies explore who could be potential users of EEA [see Schwab et al., 2017, Parker et al., 2017, Sippel et al., 2015, James et al., 2014, Stott and Walton, 2013]. In a second article, we will explore in depth the reasons why scientists do EEA, based on our two corpora of interviews. For the rest of the present article, we will avoid considerations regarding the use of EEA.

Although a part of community hence engages in a debate opposing risk-based and storyline approaches, it is not the case of the whole community. We found almost no mention of it in our interviews. Moreover, a few articles have already proposed ways to combine both approaches [Shepherd, 2016, Vautard et al., 2016, Yiou et al., 2017]. The storyline approach can be completed by an assessment of the influence of climate change on the circulation in which case, the whole event is accounted for. Stott et al. [2017] point out that "different approaches to event attribution may choose to occupy different places on the conditioning spectrum". Furthermore, authors like Pardeep Pall and Dáithí Stone have engaged in the two types of approaches [Pall et al., 2011, 2017].

\section{The classification of the BAMS}

This section explains how we approached the classification of the 105 case studies from the BAMS. We first tried to sort them between risk-based and storyline approach (in the sense of Shepherd [2016], which includes Otto [2017]'s Boulder approach). This proved difficult because a lot of articles do not fall into either categories, or fall into both.

We then analyzed the genealogy of each article, in order to identify common methodologies. In supplementary table $\mathrm{S} 4$, we list all the case studies. We put an article in the genealogy column 
when the authors explicitly state their method is based on another article. The supplementary table S5.1 sums up our findings regarding this explicit genealogy of BAMS articles.

Stott et al. [2016] present a review of the different methodologies to do EEA. They distinguish methodologies between coupled model methods, sea surface temperature (SST) forced atmosphere only model methods, analogue-based methods, empirical methods and broad-scale methods (they use the word "approaches" instead of "methods", but we changed it to "methods" in order to avoid a confusion with risk-based and storyline approaches).

Our BAMS analysis shows that those different methods do not have the same popularity. The coupled model methods cover a large spread of methodologies, so we do not consider that all articles using coupled models should be part of the same category. Lewis and Karoly [2013, 2014], Sun et al. [2014], King et al. [2015] have been cited several times by BAMS articles relying on the comparison of probabilities for different CMIP5 experiments for their analysis. Many other articles use this methodology without explicitly refering to a former article.

The most used methodology, also described as the SST forced method by Stott et al. [2016], stems from Pall et al. [2011], and has been refined by Massey et al. [2015], Schaller et al. [2014], Black et al. [2015] and Schaller et al. [2016]. 21 BAMS articles cite at least one of those articles. This methodology is the one that fits best the risk-based approach. 5 BAMS articles cite Christidis et al. [2013] which also use a large ensemble of an atmospheric model with different SST forcings for a part of their analysis.

4 articles (all from the same team) use the analogue methodology to perform a conditional attribution. They all cite Cattiaux et al. [2010] as the first article to study a specific event in the context of climate through the use of analogues. Articles with a methodology similar to what Stott et al. [2016] call empirical methods cite either Van Oldenborgh et al. [2012], Coles et al. [2001] or do not reference a former article using this methodology [e.g. Siswanto et al., 2015]. It is almost never the only methodology used in those articles [e.g. Sippel et al., 2016]. The broad-scale methods [e.g. 
Zwiers et al., 2011, Min et al., 2011] are more detection and attribution of trends on extremes than EEA. We did not find references to those articles in BAMS case studies.

Four other methodologies in the BAMS are used in at least 3 different articles which are not presented in Stott et al. [2016] and for which we hence give more details. Knutson et al. [2013b] question whether the models are able to reproduce the observed event with pre-industrial runs and with historical runs. They plot the evolution of the observed trend of the variable of interest (e.g. the mean spring temperature in the Eastern United States) with the starting year of the trend. They compare those observed trends with the ensemble of trends for both natural and anthropogenic forcings from CMIP5 models to see if the observed trends are consistent with climate variability alone. This approach lies in between detection and attribution of trends and EEA. We found 7 articles using this methodology in the BAMS.

The strategy of Arblaster et al. [2014] is to determine which parameters - among which climate change - are necessary to reproduce the observed anomaly — of temperature in this case. The coupling of a seasonal forecast system and of a multiple linear regression allows the authors to reconstitute the temperature and consider which physical processes were the most important predictors for the extreme event to happen. One of these predictors is the global mean temperature, the change of which has been attributed to climate change. The authors refer to this as a "multi-step attribution process". 3 BAMS articles from the same team (including Arblaster et al. [2014]) use this methodology.

Guemas et al. [2013], Massonnet et al. [2015] and Fučkar et al. [2016] are case studies dealing with anomalies of sea ice extent. They rely on the reconstitution of anomalies with different initializations using a sea ice model. Murakami et al. [2015], Yang et al. [2015] and Zhang et al. [2016] examine tropical storms. They use forecast-oriented model simulations with different initializations to analyze the influence of climate change on those events.

Apart from the analogues, the papers based on Christidis et al. [2013] also analyze the events 
with a circulation conditional framing. Those articles could fit in both a storyline and a risk-based approach. A few individual papers could also fit into a storyline framing [e.g. De Vries et al., 2013, Sweet et al., 2013]. However, the storyline approach lacks at the moment a widespread methodology like the one of Pall et al. [2011] is for the risk-based approach. This could be due to the fact that the storyline approach as proposed by Trenberth et al. [2015] emerged after a few of the BAMS reports were already published. This under-representation may also be related to the very short length of BAMS articles, which does not fit as well the storyline approach than the risk-based approach. This does not mean that no article use this kind of approach. Outside of the BAMS, Hoerling et al. [2013], Meredith et al. [2015], and Pall et al. [2017] are three examples of storyline approaches.

The most important result of this genealogical sorting is that most of the BAMS papers follow their own methodology, specific to the case study or to a given framing. Indeed, only 51 out of 105 BAMS articles explicitly mention a genealogical link, which is mentioned in another BAMS case study. We hence propose hereafter a way to describe all the potential framings of EEA, without relying on a sorting of different methodologies.

\section{Defining EEA}

We have found that sorting the case studies between methodologies excludes most of the BAMS articles. This means that trying to categorize the case studies into different approaches or methodologies does not suffice to give a proper overview of EEA. However, the framing of EEA has a clear impact on the results of any given case studies. Angélil et al. [2017] have shown how the results of all the BAMS articles from year 2011 to 2014 would differ using a different method than the one used by the original authors. Dole et al. [2011] and Rahmstorf and Coumou [2011] find apparently contradictory results regarding the attribution of the 2010 Russian heatwave due to different framings [Otto et al., 2012].

We propose hereafter to differentiate the ways to frame EEA based on several criteria. In order 
to do so, we first need a definition EEA that captures all the different possible framings. We build it from the definitions of the relevant actors: the researchers working on EEA. We select the elements common to all of their definitions and we do not keep those which do not apply to every point of view in order to get the most consensual picture.

From both corpora of interviews we have asked 19 climatologists who have published papers on the subject to define EEA (question 2 in SM.1 and 3bis in SM.2). The most relevant excerpts of their interviews on that question are listed in the SM.3. Through the analysis of the lexical fields used in those answers we found a few elements that come back frequently when a researcher defines what is EEA. We have sorted them in the following categories:

1. the notion of causation

2. the study of one specific extreme event

3. the relationship with anthropogenic climate change and natural variability

4. the use of statistics

5. the understanding of physical processes explaining the extreme

6. the detection of a change

The three first points seem to relate to almost all the answers. When they do not appear explicitly they are implied. EEA deals with what causes a specific extreme event, in relation with climate change. The fourth and fifth categories could be considered as references to the debate between risk-based and storyline approach we exposed in section 2, which seems to be ingrained in a part of the community. However, because we have shown that this debate is not essential to define EEA (in agreement with Shepherd [2016] and Stott et al. [2017]), we will not keep those elements as parts of our working definition of EEA.

The 6th category is probably an artifact related to the fact that the word "detection" was used in the $\mathrm{A} 2 \mathrm{C} 2$ corpus and not in the EUCLEIA corpus. This may be related to the fact that we asked researchers to define detection and attribution of extreme events in the $\mathrm{A} 2 \mathrm{C} 2$ corpus, rather than 
EEA, as done in the EUCLEIA corpus. We hence find it best not to consider it for our definition, since detection (in the sense of Hegerl et al. [2010]) is rarely a part of EEA studies.

Our working definition has to adopt the widest possible scope so as to include every acceptation of EEA and to discuss their differences. Building on the three first categories, we propose to define EEA as the ensemble of scientific ways to interpret the question "was this event influenced by climate change?" and answer it. We avoid references to causality, as advised in chapter 2 of NAS2016. We choose to refer to climate change and not anthropogenic climate change, as EEA could be applied to changes not related to anthropogenic activities (e.g. volcanic eruptions). Questions like "how the probability of an event is affected by climate change?", or "how climate change modified the physics of an event?" are different reformulations of the question "was this event influenced by climate change?" in a suitable way to make it possible to answer through a scientific study.

\section{Framing EEA}

We can use this definition to show all the possible framings of an EEA study. In order to do so, we decompose the original question "was this event influenced by climate change?" into three separate issues. First, how does one define the event to study? Second, what does one mean by "influenced by"? Third, how does one represent climate change? This partition and the variation of answers to those three questions allow us to give a better picture of the subtleties of EEA and to detail the choices one has to do to propose a methodology to study a given event.

\subsection{The event}

\subsubsection{Class of events and singular event}

Before explaining the different ways to define the event to study, we go back to the question "what is the meaning of the word event?". There is a matter of whether we really consider a singular event or a class of event. In the first case, it would mean answering whether the exact event is 
influenced by climate change. In the second case, it would mean answering whether all the events within a class (e.g. all the heatwaves above a certain threshold of temperature for a given number of consecutive days) become more likely because of climate change. Harrington [2017] has shown how those two different choices can lead to different results.

The attribution of a singular event is contingent upon the idea that somehow, the causal chains leading to this event may be reproduced in whole or in part. The idea is to recreate the same event and to evaluate how this event fares with and without climate change. Until now, this has been done in 3 different ways. Hannart et al. use data assimilation that allows them to constrain the event to its observed trajectory in a model. Meredith et al. [2015] condition strictly the circulation of their model to the one observed during the very high precipitations they are interested in. Then, they run their model for 2 different level of GHG emissions and SST corresponding to a factual and a counterfactual world. Arblaster et al. [2014] try to recreate the precise pattern of temperature anomaly observed during a heatwave by modeling several physical processes.

The attribution of a class of event is probabilistic. The goal is to evaluate if there is a change of the probability that any extreme event that shares its extreme feature with the event of interest happens due to climate change. This is mainly done by considering all the events above a certain threshold. Many studies use the observed extreme anomaly of the variable of interest as this threshold. Others choose a lower threshold, especially when the event is so extreme that it would be difficult to trust statistical tests too far in the tail of the distribution (as was done in Stott et al. [2004]). In that case, there is no need for the event to actually happen to do an EEA study. One just needs to choose a threshold, a duration and a region [Christidis et al., 2015]. A few methodologies rely on different ways to define a class of event, e.g. the ones based on analogues of circulation.

\subsubsection{Choice of the event}

Apart from those general considerations on the meaning an "event", before starting an EEA study one has to choose the event of interest. There are different reasons to consider an event to be inter- 
esting enough to study. It can be because of its impacts, its rarity, or both. We provide an overview of those motivations in supplementary Table S5.2.1. In the BAMS reports, out of 105 articles, 33 explain their interest in an event based solely on its rarity, 27 based solely on its impacts and 42 based on both. This does not mean that there are no other implicit reasons involved in the choice of a specific event. 11 articles advance different reasons (for a more comprehensive list of those reasons, consult the supplementary Table S4). For example, King et al. [2015] chose an event because it raised the media attention. We also stress that the impacts can go from very serious (e.g. "a tragic food crisis that led to famine conditions" in Funk [2012]) to rather harmless (e.g. the well-being of tennis players during the Australian Open [King et al., 2015]).

There is also the matter of the selection of the region where the event happened, which we sum up in supplementary Table S5.2.2. Most of the time, researchers study events happening in the region where they live. Out of the 105 case studies in the BAMS, 80 focus on the region of the first author's laboratory. 69 study events happening in Annex I countries, as defined by the UNFCCC, 29 focus on non Annex I countries and the rest (7 out of 105) look at polar regions or the ocean. Hence there is a disproportion of case studies in favour of developed countries (this was also pinpointed by Stott et al. [2016] and Angélil et al. [2017]). This selection bias is heightened by the fact that climatologists are aware of the events happening in their own countries because they see them happening, while they might not pay attention to extreme events happening on the other side of the world otherwise than through media reports of their impacts.

Sometimes, local stakeholders play a part in motivating researchers to study a particular event. One of our interviewees told us that "policy makers [...] had questions about [an] event because they are of course concerned about whether or not the same kind of event might happen [again]". Regional projects also mainly finance studies about local events. For example, the EUCLEIA consortium produced 6 case studies about European extreme events [e.g. Hauser et al., 2017, Wilcox et al., 2017], and the French project Extremoscope financed research focused on extreme events affecting France [e.g. Ouzeau et al., 2016]. A few stakeholders, like the Red Cross which worked with the World Weather Attribution project [Herring et al., 2016b] or UK's National Environment 
Research Council which funded the ACE (Attributing Impacts of External Climate Drivers on Extreme Weather) Africa project (e.g. see the acknowledgment of Bergaoui et al. [2015]), also support research studying developing countries which do not have research infrastructures that can lead such studies.

This selection bias has societal impacts. Huggel et al. [2016] argue that the countries which would most benefit from EEA, especially in the context of loss and damage, are also those where there are no EEA case studies. The number of studies of extreme events happening in underrepresented countries, which are also the most vulnerable, nonetheless keeps increasing with each BAMS issue [Stott et al., 2016].

\subsubsection{Precise definition of the event}

Once one has chosen an event, there are three choices left: the precise definition of the region affected, the time period to study, and the variable that will best represent the event. For the same event, different studies address those questions differently. For example in the BAMS report on 2013 extreme events, 3 articles deal with the Californian drought. Swain et al. [2014] consider a yearly event, Wang and Schubert [2014] focus on January and February, while Funk et al. [2014] study the winter season from November to February. Most of (if not all) the time, those choices are arbitrary, meaning that they do not arise from scientific considerations, but rather from political borders, or from regions defined in earlier articles that might not be relevant for the specific event of interest. Cattiaux and Ribes [2018] propose to optimize both of those choices by selecting the region and period for which the event has the lowest probability of occurrence. This could be a way to study the most extreme events, and to objectify the choice of a region and a time period.

\subsection{Influence of climate change: level of conditioning}

The second part of the decomposition of the question "was this event influenced by climate change ?" is to show all the different ways to analyze the role of climate change. In order to sort them, 
we follow NAS2016, which divides EEA between two types of methodologies: unconditional and conditional attribution. We have classified all the BAMS articles between different nuances of conditioning. We divided the articles into the following categories (see supplementary table S5.3 for an overview):

- Unconditional - 42

- Conditional to SST/SIC (sea ice cover) - 40

- Conditional to circulation - 9

- Conditional to El Niño/La Niña - 9

- Conditional to sea level rise -2

- Effects of anthropogenic climate change on a precursor - 13

- Effect of other precursors than anthropogenic climate change -29

We say that attribution is unconditional when the study directly links anthropogenic climate change to an extreme observable, or its impacts. That can only happen in studies using either only observations or coupled models (CMIP5 or studies focused on a particular model) with a comparison between pre-industrial (or natural-forcings only) and historical runs. This does not mean that those studies are not conditional to the biases of the models they rely on. Examples of unconditional attribution in the BAMS are the papers of Lewis and Karoly [2014] or Knutson et al. [2013a].

Conditional attribution links anthropogenic climate change combined to a precursor to either an extreme observable, or its impacts. This precursor is an internal element of the climate system which played a role in the occurrence of the event. Many studies, especially the ones based on the most widely used methodology proposed by Pall et al. [2011] evaluate the influence of a thermodynamical precursor combined with greenhouse gases (GHG) concentrations on an extreme observable (e.g. temperature, or precipitation). A thermodynamical precursor is a precursor that is directly linked to the increase of temperatures and for which the influence of climate change 
is already clear. Most of the time the thermodynamical precursor is the sea-surface temperature (SST). Because of the computational costs of coupled models, the idea is to rely on atmosphericonly models, for which the SST is a boundary condition. They allow to better represent processes like dynamics or land-surface interactions which become more trustworthy at high resolutions.

According to Risser et al. [2017], the SST conditioning methods rely on three assumptions: (i) the effect of anthropogenic climate change does not depend on the state of the ocean, (ii) the ocean variability is not affected by anthropogenic climate change, and (iii) the effect of the atmosphere on the coupling between atmosphere and ocean is unimportant at the temporal scale of the event. The influence of SST conditioning, which is massively used in the EEA literature has not been enough documented to make the assumption that the probabilities calculated are equivalent to unconditional probabilities. Dong et al. [2017] have shown that this assumption is globally correct for temperature extremes but that the air-sea coupling significantly changes the results for precipitations and in certain regions for the circulation. Risser et al. [2017] also provide a methodology to evaluate the influence of the SST conditioning on EEA results. Other possible thermodynamical precursor are the global temperature [e.g. Hope et al., 2015] or sea level rise [e.g. Sweet et al., 2013].

Conditioning can also combine climate change to a precursor not clearly related to climate change through thermodynamics, a dynamical precursor. This type of conditional attribution is the one presented in Trenberth et al. [2015], which Shepherd [2016] called "storyline approach". The idea is that for events heavily conditioned by the dynamics, the climate change signal will be drowned in the internal variability. This does not mean that there is no effect of climate change. The question asked in this case would rather be "Given the change in atmospheric circulation that brought about the event, how did climate change alter its impacts ?" [Trenberth et al., 2015] or "What is the best estimate of the contribution of climate change to the observed event?" [Shepherd, 2016].

There are examples of other types of conditioning dealing with other scales of internal variability. 9 BAMS articles study the influence of El Niño (or La Niña) on an event combined with the 
influence of climate change on El Niño [e.g. King et al., 2013].

13 case studies focus on the role of climate change on a specific precursor of the event without attributing the event itself to climate change. For example, Funk [2012] calculate the Indian-Pacific warm pool (IPWP) enhancement by climate change. They rely on the literature to link the IPWP warming to droughts in Eastern Africa, which were their event of interest.

29 case studies also consider the impacts of other precursors than anthropogenic climate change. Most of these studies (22) are combined with a part discussing the role of climate change. The methodology of Arblaster et al. [2014] summarized in the third section gives an example of such an approach. The fact that 7 BAMS studies analyse only the effect of other precursors than anthropogenic climate change shows that EEA can encompass attribution to climate change more generally than just anthropogenic climate change.

Lastly, Von Storch et al. [2014] and Feser et al. [2015] only detect changes without any attribution step so we could not sort them.

An interesting result of sorting BAMS studies into different levels of conditioning is that each issue of the BAMS increases the sampling of uses of different methods and the comparison of their results. Those studies are highlighted in boldface in the supplementary table S5.3. This is consistent with the recommendations of NAS2016 [2016]. The EUCLEIA project has also devoted one work package to multi-method case studies [e.g. Hauser et al., 2017, Wilcox et al., 2017].

\subsection{Climate change: Definition of a counterfactual world}

EEA usually relies on the comparison of a factual and a counterfactual world. The difference between these worlds is the key to calculate the role of climate change. Their definitions vary from one study to the other. To build a counterfactual world, one has to decide how far back to anthropogenic emissions one needs to go to represent a world without climate change. There are several 
ways to compare worlds with and without climate change. We have sorted the different ways to create a counterfactual world in the following categories (supplementary table S5.4 gives the detail of how we classified each BAMS article):

- Past/Historical - 24

- SST/SIC/GHG Preindustrial - 21

- SST/SIC/GHG Natural - 9

- SST/SIC/GHG Historical - 13

- Natural forcings only - 17

- Preindustrial - 22

- Not relevant - 15

The simplest way to procede is to compare a past period to a most recent period, whether it is in observational datasets, or in the historical period of a climate model. This will not give a complete account of the effects of climate change, as the world of the past might already be affected by anthropogenic emissions. The main advantage (and disadvantage, given the length and availability of the observational datasets) of this technique is that it allows to rely on observations only [e.g. Van Oldenborgh et al., 2012]. In this context, climate change accounts for both anthropogenic and natural forcings.

Other studies use pre-industrial runs from coupled models as counterfactual worlds. There is a thin line between a definition of the counterfactual based on the past and the counterfactual based on pre-industrial conditions. Sometimes the word pre-industrial is not explicitly stated but when the reference is a past climate of before 1900 we sorted it as pre-industrial [e.g. Barlow, 2015]. This arbitrary choice can be challenged, as Hawkins et al. [2017] have shown that 1870 does not necessarily equal preindustrial. We however choose to keep it to make the classification simpler. 
An alternative option to pre-industrial for coupled models users is to use historical runs with natural forcings only, which are available for CMIP5 models. 5 articles use both pre-industrial and natural counterfactual worlds.

For methodologies based on atmospheric models, the factual world is built using the observed SST as input. The tricky step is to create counterfactual SSTs [Schaller et al., 2016]. There is an evolution from historical (which was the counterfactual world used in Pall et al. [2011]) towards preindustrial through the BAMS issues. Otto [2017] also discusses the consequences of the differences between counterfactual worlds in the context of SST conditional attribution.

The use and comparison of several counterfactual worlds does not occur as frequently in the BAMS as the use of multiple levels of conditioning, although it does happen in the three latest issues studies here. However, there is a case for testing the influence of the choice of counterfactual on the results, since Hauser et al. [2017] have shown that it has an impact on the result.

In the BAMS, the evaluation of contributions from differentiated external forcings, like GHG and aerosols, or land-use is rarely done. In contrast with the detection and attribution of trends, one of the interviewees states that "EEA is very very predominantly envisioned in an anthropogenic vs natural perspective, and only with this reading grid". There are very few studies differentiating the role of those different anthropogenic forcings in the BAMS. As an exception to that rule, Wilcox et al. [2015] and Miao et al. [2016] make a distinction between aerosols and GHG emissions effects on the extreme event. We also point out that Pall et al. [2011] define their counterfactual by removing only the GHG part of the anthropogenic forcing, not the aerosols.

We note that for a few articles, the explicit definition of a counterfactual world is not necessary. We sorted them as not relevant. Those articles use methodologies based on the reconstitution of an observed anomaly [e.g. Arblaster et al., 2014] or only do trend detection without any comparison to trends in a counterfactual world [e.g. Feser et al., 2015]. 


\section{Conclusion}

We have shown that the BAMS case studies use different types of methodologies, compare different datasets, and explore different conditionings in order to give a better picture of the diverse causes of an extreme event. We propose a definition of EEA that encompasses the different approaches used by the community described in section 2 . EEA is the ensemble of scientific ways to interpret the question "was this event influenced by climate change ?" and answer it. It allows us to describe the differences between framings through three main axes : how does one define the event of interest? how does one express causation? what does one mean by a world without climate change? We have described the diversity of ways to answer these questions used in the BAMS and provide a complete classification in the supplementary material.

Although the BAMS issues are a very practical database due to the common strict guidelines, they also have limitations. Indeed, a few methods (especially those following the storyline approach) have not yet been used in the BAMS [e.g. Meredith et al., 2015, Hoerling et al., 2013, Pall et al., 2017] and may never be due to the limited space allowed for each case study. This entails that while the BAMS is informative of a large part of the work of EEA, it cannot be considered as an unbiased sample.

The next step of our unveiling of EEA will be to better understand its use, as it seems to be a point of contention between the different approaches we described in section 2. A few articles have already started to tackle this question [e.g. Sippel et al., 2015, Hulme, 2014]. A second article will analyze in detail the two corpora of interviews to answer the question : "why do we do EEA?" 


\section{Acknowledgements}

This work was supported by ERC grant No. 338965-A2C2 and the European Union's Seventh Framework Programme grant No. 607085-EUCLEIA. We thank Dáithí Stone, and three anonymous reviewers for their helpful comments.

\section{References}

M. Allen. Liability for climate change. Nature, 421(6926):891-892, 2003. doi: 10.1038/421891a.

M. Allen. In defense of the traditional null hypothesis: remarks on the trenberth and curry wires opinion articles. Wiley Interdisciplinary Reviews: Climate Change, 2(6):931-934, 2011. doi: 10.1002/wcc. 145 .

O. Angélil, D. Stone, M. Wehner, C. J. Paciorek, H. Krishnan, and W. Collins. An independent assessment of anthropogenic attribution statements for recent extreme temperature and rainfall events. Journal of Climate, 30(1):5-16, 2017. doi: 10.1175/JCLI-D-16-0077.1.

J. M. Arblaster, E.-P. Lim, H. H. Hendon, B. C. Trewin, M. C. Wheeler, G. Liu, and K. Braganza. Understanding Australia's hottest September on record [in Explaining Extreme Events of 2014 from a Climate Perspective]. Bulletin of the American Meteorological Society, 95(9):S37-S41, 2014.

A. Barlow, Mathew; Hoell. Drought in the Middle East and Central Southwest Asia during winter 2013/14 [in "Explaining Extreme Events of 2014 from a Climate Perspective"]. Bulletin of the American Meteorological Society, 96(12):S71-S76, 2015.

E. A. Barnes. Revisiting the evidence linking Arctic amplification to extreme weather in midlatitudes. Geophysical Research Letters, 40(17):4734-4739, 2013. doi: 10.1002/grl.50880.

K. Bergaoui, D. Mitchell, R. Zaaboul, R. McDonnell, F. Otto, and M. Allen. The contribution of human-induced climate change to the drought of 2014 in the Southern Levant region [in "Explaining Extreme Events of 2014 from a Climate Perspective"]. Bulletin of the American Meteorological Society, 96(12):S66-S70, 2015. 
M. T. Black, D. J. Karoly, and A. D. King. The contribution of anthropogenic forcing to the Adelaide and Melbourne, Australia, heat waves of January 2014 [in "Explaining Extreme Events of 2014 from a Climate Perspective"']. Bulletin of the American Meteorological Society, 96(12): S118-S121, 2015.

J. Cattiaux and A. Ribes. Defining single extreme weather events in a climate perspective. Bull. Amer. Meteorol. Soc., 2018. doi: 10.1175/BAMS-D-17-0281.1.

J. Cattiaux, R. Vautard, C. Cassou, P. Yiou, V. Masson-Delmotte, and F. Codron. Winter 2010 in Europe: A cold extreme in a warming climate. Geophysical Research Letters, 37(20):1-6, 2010. doi: 10.1029/2010GL044613.

N. Christidis, P. A. Stott, A. A. Scaife, A. Arribas, G. S. Jones, D. Copsey, J. R. Knight, and W. J. Tennant. A new hadgem3-a-based system for attribution of weather- and climate-related extreme events. Journal of Climate, 26(9):2756-2783, 2013. doi: 10.1175/JCLI-D-12-00169.1.

N. Christidis, P. A. Stott, and F. W. Zwiers. Fast-track attribution assessments based on precomputed estimates of changes in the odds of warm extremes. Climate Dynamics, 45(5):15471564, sep 2015. doi: 10.1007/s00382-014-2408-x.

S. Coles, J. Bawa, L. Trenner, and P. Dorazio. An introduction to statistical modeling of extreme values, volume 208. Springer, 2001.

Committee on Extreme Weather Events and Climate Change Attribution (NAS2016). Attribution of Extreme Weather Events in the Context of Climate Change. 2016. doi: 10.17226/21852.

J. Curry. Nullifying the climate null hypothesis. Wiley Interdisciplinary Reviews: Climate Change, 2(6):919-924, 2011. doi: 10.1002/wcc.141.

H. De Vries, R. Van Westrhenen, and G. J. Van Oldenborgh. The February 2012 European cold spell that didn't bring the dutch another 11-city tour [in "Explaining Extreme Events of 2012 from a Climate Perspective"]. Bulletin of the American Meteorological Society, 94(9):S26-S28, 2013. 
R. Dole, M. Hoerling, J. Perlwitz, J. Eischeid, P. Pegion, T. Zhang, X. W. Quan, T. Xu, and D. Murray. Was there a basis for anticipating the 2010 Russian heat wave? Geophysical Research Letters, 38(6):1-5, 2011. doi: 10.1029/2010GL046582.

B. Dong, R. T. Sutton, L. Shaffrey, and N. P. Klingaman. Attribution of Forced Decadal Climate Change in Coupled and Uncoupled OceanAtmosphere Model Experiments. Journal of Climate, 30(16):6203-6223, 2017. doi: 10.1175/JCLI-D-16-0578.1.

F. Feser, M. Barcikowska, S. Haeseler, C. Lefebvre, M. Schubert-Frisius, M. Stendel, H. von Storch, and M. Zahn. Hurricane Gonzalo and its extratropical transition to a strong European storm [in "Explaining Extreme Events of 2014 from a Climate Perspective"]. Bulletin of the American Meteorological Society, 96(12):S51-S55, 2015.

J. A. Francis and S. J. Vavrus. Evidence linking Arctic amplification to extreme weather in midlatitudes. Geophysical Research Letters, 39(February):1-6, 2012. doi: 10.1029/2012GL051000.

N. S. Fučkar, F. Massonnet, V. Guemas, J. García-Serrano, B. O., F. J. Doblas-Reyes, and A. M. Record-low Northern Hemisphere sea ice extent in March 2015 [in "Explaining Extreme Events of 2015 from a Climate Perspective"]. Bulletin of the American Meteorological Society, 97(12): S136-S140, 2016.

C. Funk. Exceptional warming in the Western Pacific-Indian ocean warm pool has contributed to more frequent droughts in Eastern Africa [in "Explaining Extreme Events of 2011 from a Climate Perspective"]. Bulletin of the American Meteorological Society, 93(7):1049-1051, 2012.

C. Funk, A. Hoell, and D. Stone. Examining the contribution of the observed global warming trend to the California droughts of 2012/13 and 2013/14 [in Explaining Extreme Events of 2013 from a Climate Perspective]. Bulletin of the American Meteorological Society, 95(9):S11-S15, 2014.

V. Guemas, F. J. Doblas-Reyes, A. Germe, M. Chevallier, and D. Salas y Mélia. September 2012 Arctic sea ice minimum: Discriminating between sea ice memory, the August 2012 extreme storm, and prevailing warm conditions [in "Explaining Extreme Events of 2012 from a Climate Perspective"]. Bulletin of the American Meteorological Society, 94(9):S20-S22, 2013. 
A. Hannart, A. Carrassi, M. Bocquet, M. Ghil, P. Naveau, M. Pulido, J. Ruiz, and P. Tandeo.

L. J. Harrington. Investigating differences between event-as-class and probability density-based attribution statements with emerging climate change. Climatic Change, 141(4):641-654, 2017. doi: 10.1007/s10584-017-1906-3.

M. Hauser, L. Gudmundsson, R. Orth, A. Jézéquel, K. Haustein, R. Vautard, G. J. V. Oldenborgh, L. Wilcox, and S. I. Seneviratne. Methods and model dependency of extreme event attribution: The 2015 European drought. Earth's Future, 2017. doi: 10.1002/eft2.256.

K. Haustein, F. E. L. Otto, P. Uhe, and N. Schaller. Real-time extreme weather event attribution with forecast seasonal SSTs. Environmental Research Letters, 11(6):1-15, 2016. doi: 10.1088/17489326/11/6/064006.

E. Hawkins, P. Ortega, E. Suckling, A. Schurer, G. Hegerl, P. Jones, M. Joshi, T. J. Osborn, V. Masson-Delmotte, J. Mignot, P. Thorne, and G. J. van Oldenborgh. Estimating changes in global temperature since the preindustrial period. Bulletin of the American Meteorological Society, 98(9):1841-1856, 2017. doi: 10.1175/BAMS-D-16-0007.1.

G. C. Hegerl, O. Hoegh-Guldberg, G. Casassa, M. P. Hoerling, R. Kovats, C. Parmesan, D. W. Pierce, and P. A. Stott. Good practice guidance paper on detection and attribution related to anthropogenic climate change. In Meeting Report of the Intergovernmental Panel on Climate Change Expert Meeting on Detection and Attribution of Anthropogenic Climate Change. IPCC Working Group I Technical Support Unit, University of Bern, Bern, Switzerland, 2010.

S. C. Herring, M. P. Hoerling, T. C. Peterson, , and P. A. Stott. Explaining extreme events of 2013 from a climate perspective. American Meteorological Society, 95(9):1-96, 2014. doi: 10.1175/1520-0477-95.9.S1.1.

S. C. Herring, M. P. Hoerling, J. P. Kossin, T. C. Peterson, and E. Stott P. A. Explaining Extreme Events of 2014 from a Climate Perspective. Bulletin of the American Meteorological Society, 96 (12):S1-S172, 2015.

S. C. Herring, A. Hoell, M. P. Hoerling, J. P. Kossin, C. J. Schreck III, and E. Stott P. A. Explaining 
Extreme Events of 2015 from a Climate Perspective. Bulletin of the American Meteorological Society, 97(12):S1-S145, 2016a.

S. C. Herring, M. P. Hoerling, J. P. Kossin, C. J. Schreck III, T. C. Peterson, and S. P. A. Introduction to Explaining Extreme Events of 2015 from a Climate Perspective. Bulletin of the American Meteorological Society, 97(12):S1-S4, 2016b.

S. C. Herring, N. Christidis, A. Hoell, J. P. Kossin, C. J. Schreck III, and E. Stott P. A. Explaining Extreme Events of 2016 from a Climate Perspective. Bulletin of the American Meteorological Society, 99:S1-S157, 2018

M. Hoerling, A. Kumar, R. Dole, J. W. Nielsen-Gammon, J. Eischeid, J. Perlwitz, X. W. Quan, T. Zhang, P. Pegion, and M. Chen. Anatomy of an extreme event. Journal of Climate, 26(9): 2811-2832, 2013. doi: 10.1175/JCLI-D-12-00270.1.

P. Hope, E.-P. Lim, G. Wang, H. H. Hendon, and J. M. Arblaster. Contributors to the record high temperatures across Australia in late spring 2014 [in ”Explaining Extreme Events of 2014 from a Climate Perspective"]. Bulletin of the American Meteorological Society, 96(12):S149-S153, 2015.

C. Huggel, I. Wallimann-Helmer, D. Stone, and W. Cramer. Reconciling justice and attribution research to advance climate policy. Nature Climate Change, 6(10):901-908, 2016. doi: 10.1038/nclimate3104.

M. Hulme. Attributing weather extremes to climate change: A review. Progress in Physical Geography: Earth and Environment, 38(4):499-511, 2014. doi: 10.1177/0309133314538644.

R. James, F. Otto, H. Parker, E. Boyd, R. Cornforth, D. Mitchell, and M. Allen. Characterizing loss and damage from climate change. Nature Climate Change, 4(11):938-939, 2014. doi: 10.1038/nclimate2411

A. D. King, S. C. Lewis, S. E. Perkins, L. V. Alexander, M. G. Donat, D. J. Karoly, and M. T. Black. Limited evidence of anthropogenic influence on the 2011-2012 extreme rainfall over Southeast Australia [in "Explaining Extreme Events of 2012 from a Climate Perspective"]. Bulletin of the American Meteorological Society, 94(9):S55-S58, 2013. 
A. D. King, M. T. Black, D. J. Karoly, and M. G. Donat. Increased likelihood of Brisbane, Australia G20 heat event due to anthropogenic climate change [in "Explaining Extreme Events of 2014 from a Climate Perspective"]. Bulletin of the American Meteorological Society, 96(12):S141S144, 2015.

T. R. Knutson, F. Zeng, and W. andrew T. The extreme March-May 2012 warm anomaly over the Eastern United States: global context and multimodel trend analysis [in "Explaining Extreme Events of 2012 from a Climate Perspective"]. Bulletin of the American Meteorological Society, 94(9):S13-S17, 2013a.

T. R. Knutson, F. Zeng, and A. T. Wittenberg. Multimodel Assessment of Regional Surface Temperature Trends: CMIP3 and CMIP5 Twentieth-Century Simulations. Journal of Climate, 26 (22):8709-8743, 2013b. doi: 10.1175/JCLI-D-12-00567.1.

S. C. Lewis and D. J. Karoly. Anthropogenic contributions to australia's record summer temperatures of 2013. Geophysical Research Letters, 40(14):3705-3709, 2013. doi: 10.1002/grl.50673.

S. C. Lewis and D. J. Karoly. The role of anthropogenic forcing in the record 2013 Australiawide annual and spring temperatures [in Explaining Extreme Events of 2013 from a Climate Perspective]. Bulletin of the American Meteorological Society, 95(9):S31-S34, 2014.

M. E. Mann, E. A. Lloyd, and N. Oreskes. Assessing climate change impacts on extreme weather events: the case for an alternative (Bayesian) approach. Climatic Change, 144(2):131-142, sep 2017. doi: 10.1007/s10584-017-2048-3.

N. Massey, R. Jones, F. E. L. Otto, T. Aina, S. Wilson, J. M. Murphy, D. Hassell, Y. H. Yamazaki, and M. R. Allen. weather@ homedevelopment and validation of a very large ensemble modelling system for probabilistic event attribution. Quarterly Journal of the Royal Meteorological Society, 141(690):1528-1545, 2015. doi: 10.1002/qj.2455.

F. Massonnet, V. Guemas, N. S. Fukar, and F. J. Doblas-Reyes. The 2014 high record of Antarctic sea ice extent [in "Explaining Extreme Events of 2014 from a Climate Perspective"]. Bulletin of the American Meteorological Society, 96(12):S163-S167, 2015. 
E. P. Meredith, V. A. Semenov, D. Maraun, W. Park, and A. V. Chernokulsky. Crucial role of Black Sea warming in amplifying the 2012 Krymsk precipitation extreme. Nature Geoscience, 8(August), 2015. doi: 10.1038/NGEO2483.

C. Miao, Q. Sun, D. Kong, and Q. Duan. Record-breaking heat in Northwest China in July 2015: analysis of the severity and underlying causes [in "Explaining Extreme Events of 2015 from a Climate Perspective"]. Bulletin of the American Meteorological Society, 97(12):S97-S101, 2016

S.-K. Min, X. Zhang, F. W. Zwiers, and G. C. Hegerl. Human contribution to more-intense precipitation extremes. Nature, 470:378, feb 2011. doi: 10.1038/nature09763.

H. Murakami, G. A. Vecchi, T. Delworth, K. Paffendorf, R. Gudgel, L. Jia, and F. Zeng. Investigating the influence of anthropogenic forcing and natural variability on the 2014 Hawaiian hurricane season [in "Explaining Extreme Events of 2014 from a Climate Perspective"]. Bulletin of the American Meteorological Society, 96(12):S115-S119, 2015.

F. E. Otto. Attribution of weather and climate events. Annual Review of Environment and Resources, 42(1):627-646, 2017. doi: 10.1146/annurev-environ-102016-060847.

F. E. L. Otto, N. Massey, G. J. V. Oldenborgh, R. G. Jones, and M. R. Allen. Reconciling two approaches to attribution of the 2010 Russian heat wave. Geophysical Research Letters, 39 (November 2011):1-5, 2012. doi: 10.1029/2011GL050422.

F. E. L. Otto, G. J. van Oldenborgh, J. Eden, P. A. Stott, D. J. Karoly, and M. R. Allen. The attribution question. Nature Climate Change, 6(9):813-816, 2016. doi: 10.1038/nclimate3089.

G. Ouzeau, J.-M. Soubeyroux, M. Schneider, R. Vautard, and S. Planton. Heat waves analysis over France in present and future climate: Application of a new method on the EURO-CORDEX ensemble. Climate Services, 4(Supplement C):1-12, 2016. doi: 10.1016/j.cliser.2016.09.002.

P. Pall, T. Aina, D. A. Stone, P. A. Stott, T. Nozawa, A. G. J. Hilberts, D. Lohmann, and M. R. Allen. Anthropogenic greenhouse gas contribution to flood risk in England and Wales in autumn 2000. Nature, 470(7334):382-385, 2011. doi: 10.1038/Nature09762. 
P. Pall, C. M. Patricola, M. F. Wehner, D. A. Stone, C. J. Paciorek, and W. D. Collins. Diagnosing conditional anthropogenic contributions to heavy Colorado rainfall in September 2013. Weather and Climate Extremes, 17(February):1-6, 2017. doi: 10.1016/j.wace.2017.03.004.

H. R. Parker, E. Boyd, R. J. Cornforth, R. James, F. E. L. Otto, and M. R. Allen. Stakeholder perceptions of event attribution in the loss and damage debate. Climate Policy, 17(4):533-550, 2017. doi: 10.1080/14693062.2015.1124750.

J. Perlwitz, M. Hoerling, J. Eischeid, T. Xu, and A. Kumar. A strong bout of natural cooling in 2008. Geophysical Research Letters, 36(23), 2009. doi: 10.1029/2009GL041188.

T. C. Peterson, P. A. Stott, S. Herring, F. W. Zwiers, G. C. Hegerl, S. K. Min, X. B. Zhang, G. J. van Oldenborgh, A. van Urk, M. R. Allen, C. Funk, D. E. Rupp, P. W. Mote, N. Massey, C. J. Rye, R. Jones, J. Cattiaux, P. Yiou, N. Massey, T. Aina, F. E. L. Otto, S. Wilson, R. G. Jones, and N. Christidis. Explaining Extreme Events of 2011 from a Climate Perspective. Bulletin of the American Meteorological Society, 93(7):1041-1067, 2012. doi: 10.1175/Bams-D-12-00021.1.

T. C. Peterson, M. P. Hoerling, P. A. Stott, and E. Herring S. Explaining Extreme Events of 2012 from a Climate Perspective. Bulletin of the American Meteorological Society, 94(9):S1-S74, 2013.

S. Rahmstorf and D. Coumou. Increase of extreme events in a warming world. Proceedings of the National Academy of Sciences of the United States of America, 108(44):17905-17909, 2011. doi: 10.1073/pnas.1101766108.

M. D. Risser, D. A. Stone, C. J. Paciorek, M. F. Wehner, and O. Angélil. Quantifying the effect of interannual ocean variability on the attribution of extreme climate events to human influence. Climate Dynamics, 49(9):3051-3073, Nov 2017. doi: 10.1007/s00382-016-3492-x.

N. Schaller, F. E. L. Otto, G. J. van Oldenborgh, N. R. Massey, S. Sparrow, and M. R. Allen. The heavy precipitation event of MayJune 2013 in the upper Danube and Elbe basins [in Explaining Extreme Events of 2014 from a Climate Perspective]. Bulletin of the American Meteorological Society, 95(9):S69-S72, 2014. 
N. Schaller, A. L. Kay, R. Lamb, N. R. Massey, G. J. Van Oldenborgh, F. E. Otto, S. N. Sparrow, R. Vautard, P. Yiou, I. Ashpole, et al. Human influence on climate in the 2014 southern england winter floods and their impacts. Nature Climate Change, 6(6):627, 2016. doi: 10.1038/nclimate2927.

M. Schwab, I. Meinke, J.-P. Vanderlinden, and H. von Storch. Regional decision-makers as potential users of Extreme Weather Event Attribution - Case studies from the German Baltic Sea coast and the Greater Paris area. Weather and Climate Extremes, (August 2016):1-7, 2017. doi: 10.1016/j.wace.2017.09.001.

T. G. Shepherd. A Common Framework for Approaches to Extreme Event Attribution. Current Climate Change Reports, 2(1):28-38, 2016. doi: 10.1007/s40641-016-0033-y.

S. Sippel, P. Walton, and F. E. L. Otto. Stakeholder perspectives on the attribution of extreme weather events: An explorative enquiry. Weather, Climate, and Society, 7(3):224-237, 2015. doi: 10.1175/WCAS-D-14-00045.1.

S. Sippel, F. E. L. Otto, M. Flach, and G. J. van Oldenborgh. The role of anthropogenic warming in 2015 central European heat waves[in "Explaining Extreme Events of 2015 from a Climate Perspective"]. Bulletin of the American Meteorological Society, 97(12):S51-S56, 2016.

Siswanto, G. J. van Oldenborgh, G. van der Schier, G. Lenderink, and B. van den Hurk. Trends in high-daily precipitation events in Jakarta and the flooding of January 2014 [in "Explaining Extreme Events of 2014 from a Climate Perspective"]. Bulletin of the American Meteorological Society, 96(12):S131-S135, 2015.

P. A. Stott and P. Walton. Attribution of climaterelated events: understanding stakeholder needs. Weather, 68(10):274-279, 2013. doi: 10.1002/wea.2141.

P. A. Stott, D. A. Stone, and M. R. Allen. Human contribution to the European heatwave of 2003. Nature, 432(7017):610-614, 2004. doi: 10.1038/Nature03089.

P. A. Stott, N. Christidis, F. E. L. Otto, Y. Sun, J.-P. Vanderlinden, G. J. van Oldenborgh, R. Vautard, H. von Storch, P. Walton, P. Yiou, and F. W. Zwiers. Attribution of extreme weather and 
climate-related events. Wiley Interdisciplinary Reviews: Climate Change, 7(1):23-41, 2016. doi: 10.1002/wcc.380.

P. A. Stott, D. J. Karoly, and F. W. Zwiers. Is the choice of statistical paradigm critical in extreme event attribution studies? Climatic Change, 144(2):143-150, 2017. doi: 10.1007/s10584-0172049-2.

Y. Sun, X. Zhang, F. W. Zwiers, L. Song, H. Wan, T. Hu, H. Yin, and G. Ren. Rapid increase in the risk of extreme summer heat in eastern china. Nature Climate Change, 2014. doi: 10.1038/nclimate2410.

D. L. Swain, M. Tsiang, M. Haugen, D. Singh, A. Charland, B. Rajaratnam, and N. S. Diffenbaugh. The extraordinary California drought of 2013/2014: Character, context and the role of climate change [in Explaining Extreme Events of 2013 from a Climate Perspective]. Bulletin of the American Meteorological Society, 95(9):S3-S7, 2014.

W. Sweet, C. Zervas, S. Gill, and J. Park. Hurricane Sandy inundation probabilities today and tomorrow [in "Explaining Extreme Events of 2012 from a Climate Perspective"]. Bulletin of the American Meteorological Society, 94(9):S17-S20, 2013.

K. E. Trenberth, J. T. Fasullo, and T. G. Shepherd. Attribution of climate extreme events. Nature Clim. Change, 5(8):725-730, 2015. doi: 10.1038/nclimate2657.

G. J. Van Oldenborgh, A. van Urk, and M. Allen. The absence of a role of climate change in the 2011 Thailand floods [in "Explaining Extreme Events of 2011 from a Climate Perspective"]. Bulletin of the American Meteorological Society, 93(7):1047-1049, 2012.

R. Vautard, P. Yiou, F. E. L. Otto, P. Stott, N. Christidis, G. J. van Oldenborgh, and N. Schaller. Attribution of human-induced dynamical and thermodynamical contributions in extreme weather events. Environmental Research Letters, 11(11):114009, 2016. doi: 10.1088/1748-9326/11/11/114009.

H. Von Storch, F. Feser, S. Haeseler, C. Lefebvre, and M. Stendel. A violent midlatitude storm in Northern Germany and Denmark, 28 October 2013 [in Explaining Extreme Events of 2013 from a Climate Perspective]. Bulletin of the American Meteorological Society, 95(9):S76-S78, 2014. 
H. Wang and S. Schubert. Causes of the extreme dry conditions over California during early 2013 [in Explaining Extreme Events of 2013 from a Climate Perspective]. Bulletin of the American Meteorological Society, 95(9):S7-S11, 2014.

L. J. Wilcox, B. Dong, R. T. Sutton, and E. J. Highwood. The 2014 hot, dry summer in Northeast Asia [in "Explaining Extreme Events of 2014 from a Climate Perspective"]. Bulletin of the American Meteorological Society, 96(12):S105-S110, 2015.

L. J. Wilcox, P. Yiou, M. Hauser, F. C. Lott, G. J. van Oldenborgh, I. Colfescu, B. Dong, G. Hegerl, L. Shaffrey, and R. Sutton. Multiple perspectives on the attribution of the extreme European summer of 2012 to climate change. Climate Dynamics, 2017. doi: 10.1007/s00382-017-3822-7.

P. Wolski, D. Stone, M. Tadross, M. Wehner, and B. Hewitson. Attribution of floods in the okavango basin, southern africa. Journal of Hydrology, 511:350 - 358, 2014. ISSN 0022-1694. doi: https://doi.org/10.1016/j.jhydrol.2014.01.055. URL http://www.sciencedirect.com/science/article/pii/s0022169414000778.

X. Yang, G. A. Vecchi, T. L. Delworth, K. Paffendorf, R. Gudgel, L. Jia, S. D. Underwoord, and F. Zeng. Extreme North America winter storm season of 2013/14: Roles of radiative forcing and the global warming hiatus [in "Explaining Extreme Events of 2014 from a Climate Perspective"]. Bulletin of the American Meteorological Society, 96(12):S25-S28, 2015.

P. Yiou, A. Jézéquel, P. Naveau, F. E. L. Otto, R. Vautard, and M. Vrac. A statistical framework for conditional extreme event attribution. Advances in Statistical Climatology, Meteorology and Oceanography, 3(1):17-31, 2017. doi: 10.5194/ascmo-3-17-2017.

W. Zhang, G. Vecchi, H. Murakami, G. Villarini, T. L. Delworth, K. Paffendorf, R. Gudgel, L. Jia, F. Zeng, and X. Yang. Influences of natural variability and anthropogenic forcing on the extreme 2015 accumulated cyclone energy in the Western North Pacific [in "Explaining Extreme Events of 2015 from a Climate Perspective"]. Bulletin of the American Meteorological Society, 97(12): S131-S135, 2016.

F. W. Zwiers, X. Zhang, and Y. Feng. Anthropogenic Influence on Long Return Period Daily 
Temperature Extremes at Regional Scales. Journal of Climate, 24(3):881-892, 2011. doi: 10.1175/2010JCLI3908.1. 
Click here to access/download Supplementary Material supplementary-material-1.pdf 
Click here to access/download Supplementary Material supplementary-material-2.pdf 
Click here to access/download Supplementary Material supplementary-material-3.pdf 
Click here to access/download Supplementary Material supplementary-material-4.pdf 
Click here to access/download Supplementary Material supplementary-material-5.pdf 